\title{
Reading and Effective Leadership
}

\author{
Agnes Ovayioza Enesi \\ Faculty of Education, Ahmadu Bello University, Samaru, Zaria, Nigeria \\ Email: ovayi@yahoo.com \\ Hanna Onyi Yusuf \\ Faculty of Education, Ahmadu Bello University, Samaru, Zaria, Nigeria \\ Email: hannayusuf@yahoo.com
}

\begin{abstract}
This paper deals with reading and effective leadership. It highlights the fact that every reader is a potential leader. Effective leadership is therefore hinged on acquiring essential reading skills. The paper concludes by recommending ways individuals can enhance their reading skills.
\end{abstract}

Index Terms—reading, effective leadership, leadership qualities

\section{INTRODUCTION}

Reading is a complex activity that involves both perception and thought. It consists of two related processes word recognition and comprehension. Word recognition refers to the process of perceiving how written symbols correspond to one's spoken language. Comprehension is the process of making sense of words, sentences and connected text. Readers typically make use of background knowledge, vocabulary, grammatical knowledge, experience with text and other strategies to help them understand written text.

Much of what is already known about reading is based on studies conducted in English and other alphabetic languages. Learning to read is an important educational goal for children and adults. The ability to read opens up new worlds and opportunities.

The context of leadership is also important for instance, children and adults are both leaders in their respective domains; they learn to read, either in their language or a foreign language as is the common occurrence in Nigeria. As this occurs, they are exposed to the culture of the second language. And because texts are written with a specific audience in mind, cultural knowledge is present in texts and it is assumed that the reader is familiar with such knowledge. Therefore, the reader learns the cultural, educational, leadership styles of other people/cultures, and so borrow some useful traits to be used here. Thus, to be great, whether as a scholar or a leader, one has to internalise the practice of reading because it is only in reading that one stays informed, educated and dynamic.

\section{READING DEFINED}

Many think of reading as a skill that is taught once and for all in school. Reading involves perception and cognition. According to Deaman and Alber (2005), reading is that special process that involves all other developmental processes that leads to reading mastery. Yusuf (2009) defines reading as the interactive, multilevel, orthographic, phonological, lexical, syntactic, semantic as well as discourse activities engaged by a person. She stressed that a reader's purpose in approaching a text is of vital importance. Reading becomes far more than the ability to pronounce words on a page. It involves the recognition and interpretation of symbols. It also involves using both the information provided in the text by the author as well as the resources outside the text.

Some other linguists believe that reading is a matter of maturation rather than a process developed through systematic instruction and practice. To others, reading is accurate pronunciation which emphasizes phonic instruction etc, while Smith (1973) views reading as a key to a wealth of experience that links people in ways that are unlimited. Reading provides experiences through which the individual expands academic and intellectual horizons, identifies, extends and deals with personal interests and attitudes that affect the task of reading as a whole.

Oyetunde (2009) defines reading as a process of, and an aid to information processing, and it fosters the understanding and comprehension of written text.

The Encyclopaedia Britannica (2010), Vol 23 defines reading in the following ways. Reading may refer to:

- a cognitive process of decoding symbols to derive meaning from text (as in reading a book or reading music)

- the act or medium of obtaining useful pieces of information

- interpretation: a mental representation of the meaning or significance of something.

- a process in which written information is received by the retina, processed by the primary visual cortex, and interpreted.

Most people think of reading as a simple, passive process that involves reading words in a linear fashion and internalising their meaning one at a time. But reading is actually a very complex process that requires a great deal of 
active participation on the part of the reader. To further get a better sense of the complexity of reading, read what some experts in the field have said about the reading process:

Roy (2000) says that the message is not something given in advance, or given at all, but something created by interaction between writers and readers as participants in a particular communicative situation.

Reading is asking questions of printed text, and reading with comprehension becomes a matter of getting your questions answered. (Smith, 1997).

Reading is a psycholinguistic guessing game. It involves an interaction between thought and language. Efficient reading does not result from precise perception and identification of all elements, but from skill in selecting the fervest, most productive cues necessary to produce guesses which are right (Goodman 1996).

For many years, readers have driven literacy programmes world over with this perception. First, learning to read means learning to pronounce words and second, learning to identify words to get their meanings. On the other hand, learning to read could also mean learning to bring meaning to a text in order to get meaning from it (Allington and Cunningham, 1996).

\section{The benefits of reading}

- If people develop a habit of reading, they will become more confident and self assured in abilities to comprehend and understand all information types.

- Reading exercises the mind. The mind begins to flex and bend mentally. It stays loose and limber so one can flow easier through the course of the day. The regular routine ensures that the reading muscles stay in good shape as well as the mind, just as physical exercise does.

- Reading enhances one's ability to focus. When the mind is trained and challenged, it begins to pay attention more thoroughly. Also, when people develop the habit of reading, they are building a foundation that will allow them accomplish many goals and ambitions for their lives.

- Reading is the basic foundation on which academic skills are built. In children, the right time to inculcate good habits and values in them is in their childhood. Reading enhances the child's ability to comprehend various concepts with immense ease.

- reading avails one the rare opportunities of getting literacy information through text (Widdowson, 1979)

- $t$ provides experience through which the individual expands his/her academic/intellectual horizons, (Yusuf, 2010).

- it distinguishes fact from fiction etc.

As we read, our knowledge will be broadened to a greater level that could tickle our fantacy for reading every time, and by so doing, all the written information that is needed for us to excel as a leader will be made manifest. In addition to the fact that reading ensures being informed, there is the much acclaimed belief that "readers are leaders". A leader who does not love reading, will be more unfortunate for being one.

The foremost requirement here is that parents themselves (especially the literate parents) understand the importance of reading at home in order to be able to inculcate the reading habit in their children while the illiterate parents seek the assistance of lesson teachers and tutorials.

\section{LEADERSHIP DEFINED}

Good leaders are made not born. It is often said that one that has the desire and will power, can become an effective leader. Good leaders develop through a never ending process of self study education, training and experience (Jago, 1982). This statement will serve as a guide into the definition of leadership.

The International Leadership Journal (2007) defines leadership as the process of social influence in which a person can enlist the aid and support of others in the accomplishment of a common task.

Northhouse (2007) views leadership as a process by which a person influences others to accomplish an objective and directs the organisation in a way that makes it more cohesive and coherent. It is a process whereby an individual influences a group of individuals to achieve a common goal. Leaders carry out this process by applying their leadership knowledge and skills.

Children Leadership World (CLW 2010) defines leadership as "enabling a group to engage together in the process of developing, sharing and into vision, and then living it out". Leadership entails exerting, motivating, inspiring and helping others realise their potentials.

Collins English Dictionary (1998) defines leadership as the ability to lead, while Drucker (2008) sums up the definition of leadership as "Someone who has followers".

Leadership can also be seen as the ability to inspire, motivate, direct and lead a group of people to achieve a common goal and this requires influence, intelligence, diligence, continuing education and consistent reading.

\section{A. Leadership Qualities}

\section{Honesty}

Honesty is being truthful and sincere in ones interaction and work with people. People want to follow an honest leader. When we start a leadership position, we need to assume that people will think we are a little dishonest. In order to be seen as an honest individual, we will have to go out of our way to display honesty. People will assume we are honest because we have never been caught on the wrong side. One of the most frequent places where leaders miss an 
opportunity to display honesty is in handling mistakes. Much of a leader's job is to try new things and refine the ideas that do not work and unless this is done, we cannot be honest.

Insight/Vision

There is power in vision. A leader of vision is one who has the ability to think and plan for the future with great imagination and intelligence. When people do not consider their leaders as forward-looking they (the followers) may think the leader is incapable. When a leader does not have a vision for the future, it is usually because such a leader spends much time on today, without the thought about tomorrow. Leaders should set aside time for planning, strategizing and thinking about the future.

Competence

Competence simply means the ability to do something very well when measured against standards. A leader must not necessary be the foremost expert on every area of the entire organisation but there is need to be able to demonstrate competency.

Inspiration

A true leader is one who inspires his/her followers.

Everybody wants to be inspired. In fact, there is a class of people who will follow an inspiring leader even when the leader has no other qualities. One technique to develop an ability to inspire is telling stories, and "reading". Stories can be examples from the leader's clients, customers, students or staff. Stories help a leader to illustrate vividly what he/she is trying to communicate, through reading. A leader needs to read lots of materials (past, present, future) to keep himself/herself abreast of procedures to inspire/motivate his/her followers which is one of the goals of reading: that is, to ensure that people are informed and educated.

Intelligence

Intelligence can be difficult to develop. Developing it is a lifestyle of choice. To develop intelligence, one needs to commit oneself to continual reading/learning through books. With modern advances in distance education which has taken another dimension one can take all the necessary lessons required from one's bedroom and this can only be made realistic if one internalises the fact that reading ignites and stimulates the intellect.

From the foregoing discussion one can say that by consciously making effort to exhibit the above leadership traits, people are more likely to submit themselves to you as followers. By exhibiting these qualities on regular basis, one can grow in influence. A good reader must have love for reading. It is only through reading that one can decipher meaning from text/print, in order to acquire knowledge they say is power.

Reading and effective leadership drives toward a common goal which is to achieve success. Reading is a prerequisite to measure a person's success while leadership is an act of exerting authority to accomplish a task. All of the two concepts are reinforced by someone to another.

\section{B. The Role of Reading in Developing Effective Leadership Qualities}

The challenges of effective leadership are enormous. Ziegler and Goswami (2005) said that these challenges may result in temporary questioning of ability and stability for leadership, throwing up all manner of doubts and insecurity. In developing effective leadership, they looked at it from a literal angle. First, they defined leadership development as any activity that enhances the quality of leadership within an individual or organisation. These activities ranged from programmes offered at schools, High-Ropes courses offered at Universities to executive recruits. Zhenhui (2001) added what may be termed as the great inclusion in history-"Reading". He said that although leadership development has focused on developing the leadership abilities and attitudes of individuals, the World should know that people are not all born with the ability to lead, and as such different personal discipline, characteristics, etc can help or hinder a person's leadership abilities and effectiveness. Chief among these is reading; "the ability to read and understand". Reading formalizes and brings to fruition programmes for developing leadership competences. Everyone can develop their leadership effectiveness. Achieving such developments or success takes focus, practice and persistence more akin to learning a musical instrument and / or reading a book.

The overall success of leadership development efforts has been linked to three variables:

- Individual learner characteristics

- The quality and nature of the leadership development programme

- Genuine support for behavioural change from the leader's superior (leader).

Personal learner characteristics that are associated with successful leadership development include:

- leader motivation to learn

- a high achievement drive

- personal traits such as openness to experience, an internal focus of control, and self-monitoring.

Leadership motivation springs from the idea that reading is the key to achieving leadership success. All the qualities of an efficient leader such as efficiency, uprightness, motivation/inspiration, honesty, etc do not stroll around on the street. They are imbedded in print, and to understand and carry them to the letter, the leader will have to search out and read them. Hence, reading should come first in all priorities set by a good leader.

The world is gone global. With recent studies in technologies, one is able to see the other end of the world, the cultures and economic policies through materials on the internet/books, etc. Reading thus becomes a virtue at our 
disposal which should not be neglected. For Leadership jurisdiction remains devoid of innovation and advancement without reading.

\section{LITERACY DEFINED}

Literacy development is the utmost goal of education. According to Cooper (1997) Literacy focuses on the development of the individual, who may become a leader, the personal attributes desired in a leader, desired ways of behaving, of thinking etc. Literacy development includes interpersonal relationship, the ability to decipher meaning to text, the ability to read and write, and the only way a society may develop is for its citizens to become literates. The task of obtaining literacy is a giant one and it includes.

- the ability to use written language actively and positively, This avails one the privilege of being able to read and write and use numeracy, to handle information, to express ideas and opinions to make decisions and solve problems.

- It is argued that literacy includes the cultural, political and historical contexts of the community in which communication takes place. Taking account of the fact that a large part of the benefits of literacy is obtained from having access to a literate person in the household.

- Many analysts consider literacy rates as a crucial measure to enhance a region's human capital. This claim is made on the ground that literate people can be trained less expensively than illiterate people. Generally, literates have a higher socio-economic status and enjoy better health and employment prospects.

- Literacy increases job opportunities and access to higher education.

- Literacy has also been used as a way to sort populations and control on who has access to power.

- Educators struggle to find ways to engage students in literacy development and content are exploration. Through this process, students provide an opportunity for parents and community members to see and assess their children performing culturally responsive literacy while conducting themselves in a professional manner.

\section{CONCLUSION/RECOMMENDATIONS}

Leadership is important, but it does not just happen. You can improve your leadership skills through reading (study and practice). Just as there are books such as the Bible or the Quran which one expects worshippers to be familiar with, there are also books and articles that aspiring leaders should read and study, as well. Since reading is a prerequisite to measuring a person's success, every leader should cultivate a habit of reading in order to keep leading aright. A reading leader is a winning leader anytime, any day and anywhere.

The following are some recommendations that can enhance for effective leadership through reading

- Leaders should Know how and when to apply what they read to their practice of leadership

- Just reading about leadership will not make anyone a leader except an individual wants to be one. Such individuals need to actually practise the ideas that are suggested in readable materials and incorporate them into how to lead or their leadership styles.

- It can sometimes be overwhelming, because there are lots of leadership ideas to try out. Leaders should always remember that becoming a great leader is a life-long journey, which demands time and energy. It is one step (toward greatness) at a time (Carol, 2009).

- Leaders should read an article with an eye for one idea that would strengthen their leadership skills.

- Leaders should always think of how they would practise that idea and then try them out.

- After each practice, leaders should reflect on what they will do differently next time. Practice again and again until reading becomes a habit, and success can be celebrated.

\section{REFERENCES}

[1] Allington, R.L. \& Cunningham, P.M. (1996). Schools that work: where all children read and write. New York: HarperCollins College Publishers

[2] Allington, R.L. \& Cunningham, P.M. (1998). International Reading Association for the Education of Young Children. Maryland State Department of Education, n.d; Snow, Burns and Griffin.

[3] Carol. (2009). Readings about Leadership. New York: hamper and Row

[4] Collins English Dictionary. (1998). New York; Houper Collins Publication.

[5] Christian Leadership World. (2010). Effective Leadership Traits Amazon.com

[6] Cooper, J.D. (1997). Literacy: Helping children construct meaning ( $3^{\text {rd }}$ ed.) Boston: Houghton Mifflin.

[7] Children Leadership Wold. (2010). Journal of International Leadership Forum: Boston; Massachusetts: Houghton Mifflin.

[8] Cristine, C; Cynthia, G; Lori, H; Ru h, S. (2000). What is reading: an Except from what is Reading. The Quarterly Spotlight on Reading for literacy. Vol. 22 No 3. E-voice.com.

[9] Dearman and Alber. (2005). Leadership \& Education: Two Inseparable concepts. London: McSpencer.

[10] Drucker, P. (2008). Leadership Essential: Forward to the Drucker Foundation. Ask.com (accessed 28/08/2008)

[11] Smith, F. (1997). Reading without Nonsense. IRA Journal Vol. 27. P. 769-784.

[12] Goodman, K. (1996). Journal of the Reading Specialist. Portsmouth, NH: Heinemann: pp 38-41.

[13] International Leadership Journal from e Bay.com (accessed 03/12/2001)

[14] Jago. (1982). Leadership in Africa; In Journal of Leadership and Peace, Vol. 2. Jos: LECAPS 
[15] Northhouse, G.P Leadership Theory and practice. from Amazon.co.za (accessed 20/05/2007)

[16] Oyetunde, T. (2009). Beginning Reading Scheme: Empowering Teachers to help pupils become good leaders. Jos: LEACAPS publishers.

[17] Roy, Harris. (2000). Rethinking: Writings on Reading. The free online Encyclopaedia.

[18] Smith, F (1973). Comprehension and Learning. A conceptual framework for teachers. New York: holt, Rhinehart and Winston.

[19] The International Leadership Journal Online: The free Encyclopaedia; http//leadership traits.org (accessed03/05/2007)

[20] The leadership Encyclopaedia. (2010). Vol. III. Pearson Educational Co. London, United Kingdom.

[21] The leadership Development Guide: Australian Leadership Development and Row.

[22] Werner, E; Michael C.J; Steve Zaffron \& Karil L. Granger. (2010). Introductory Reading for being a leader, and The Effective Exercise of Leadership: An ontological Model (May 6, 2010). Online: The free Wikipedia. (accessed 06/05/2010)

[23] Widdowson. (1979). "Discourse Test", paper given at Ealing College of Higher Education Conference on "The Reading Skill”.

[24] Yusuf H.O. (2009). Strategies for Improving the teaching of Reading Comprehension in Primary School. Journal of Education Research and Development: Vol 4(3) p. 3-8. Zaria: ABU Press.

[25] Yusuf, H.O. (2010). Teaching Reading Comprehension in Primary Schools: a comparative Study of language development and vocabulary methods. Published Ph.D Dissertation; Mauritius: VDM Publishing House Ltd.

[26] Zhenhui, R (2001). Teaching Reading: fitting a top-down strategy into the Chinese context, Guidelines 23,20-24.

[27] Ziegler, J.C. and Goswami, U. (2005). "Reading Acquisition, developmental dyslexia and skilled Reading across languages: a psycholinguistic grain size theory".

Agnes Ovayioza Enesi has a PhD, M. Ed. and B. Ed. Degrees in Teaching English as a Second Language (TESL) and Language Arts: English. She has teaching experience at the primary, secondary and tertiary levels of Education. For the past 19 years to date, she lectures, supervise B. Ed. Projects, Master's Thesis and Doctoral dissertations in the department of Education, English and Literary Studies of Ahmadu Bello University Zaria.

Hanna Onyi Yusuf is a seasoned Educationist and Administrator with the following qualifications; Nigerian Certificate in Education (NCE) 1984, Bachelor of Education degree (B.Ed) in Language Arts 1987, Master's degree in Teaching English as a second language (M.EdTESL) 1996, Doctor of Philosophy degree (Ph.D) in Curriculum Studies in 2005. 